\title{
"Don't Know where to Go for Help": Safety and Economic Needs among Violence Survivors during the COVID-19 Pandemic
}

\author{
Leila Wood ${ }^{1}$ (1) Elizabeth Baumler ${ }^{1} \cdot$ Rachel Voth Schrag $^{2} \cdot$ Shannon Guillot-Wright $^{1} \cdot$ Dixie Hairston ${ }^{1}$. \\ Jeff Temple ${ }^{1}$ - Elizabeth Torres ${ }^{1}$
}

Accepted: 20 December 2020 / Published online: 4 January 2021

(C) Springer Science+Business Media, LLC, part of Springer Nature 2021

\begin{abstract}
The COVID - 19 pandemic and related quarantine has created additional problems for survivors of interpersonal violence. The purpose of this study is to gain a preliminary understanding of the health, safety, and economic impacts of the COVID-19 pandemic on people that are experiencing or have previously experienced violence, stalking, threats, and/or abuse. An online survey, open from April to June 2020, was taken by people with safety concerns from interpersonal violence. Participants were recruited from IPV and sexual assault-focused agencies, state coalitions, and social media. Quantitative data were summarized using descriptive methods in SPSS and coding methods from thematic and content analysis was used to analyze qualitative data from open-ended questions. A total of 53 participants were recruited for the survey. Individuals with safety concerns have experienced increased challenges with health and work concerns, stress from economic instability, difficulties staying safe, and access resources and support. Over $40 \%$ of participants reported safety had decreased. Use of social media and avoidance strategies were the most common safety approaches used. Participants reported mixed experiences with virtual services. The COVID-19 pandemic has exacerbated existing structural concerns for survivors of violence like IPV and sexual assault. Increased support and economic resource access, coupled with modified safety planning and improved virtual approaches, would better help meet survivor needs.
\end{abstract}

Keywords Safety planning $\cdot$ Virtual services $\cdot$ Domestic violence $\cdot$ Coronavirus

Globally, the COVID-19 pandemic has impacted nearly all aspects of daily life, from interacting with informal support networks to accessing routine healthcare. An overlooked consequence of the pandemic is the increased risk of intimate partner violence (IPV) and sexual assault, resulting negative impacts, and the ability of survivors to access supportive services (Boserup et al. 2020; Kaukinen 2020). The novelty and speed of the COVID-19 pandemic has drastically altered the lives of survivors of violence, bringing new challenges and concerns alongside existing inequities. Preliminary evidence

Leila Wood

leiwood@utmb.edu

1 Department of Obstetrics and Gynecology, Center for Violence Prevention, The University of Texas Medical Branch, 301 University Blvd, Galveston, TX 77555-0587, USA

2 The University of Texas at Arlington, PO Box 19129, 211 South Cooper Street, Arlington, TX 76019-0129, USA indicates that both the rate and severity of IPV, sexual assault, and other forms of interpersonal violence have increased in the wake of "stay-at-home" and social distancing guidelines related to COVID-19 and concomitantly, reporting and service access have declined (Jaramillo 2020; Piquero et al. 2020). In addition to exacerbating existing risk factors for IPV and sexual assault, such as isolation, economic insecurity, and lack of resources (Danis and Bhandari 2010), the COVID19 pandemic is occurring alongside what is often referred to as a "second" pandemic of racial injustice in the United States (Baker 2020; Geiger 1997). Black indigenous people of color (BIPOC) are at increased risk for both IPV and sexual assault (Smith et al. 2017; Cheng and Lo 2016; Stockman et al. 2015) and COVID-19 (National Medical Association 2020; Tai et al. 2020) due to systemic barriers, creating potential for additional risk for BIPOC survivors during the pandemic.

While scholars have posited on the many challenges the COVID-19 pandemic has brought to survivors of violence (Kaukinen 2020), there is little data directly from those with active safety concerns about their needs during this time. To 
help address this gap, the current study recruited participants from IPV and sexual assault services to survey 53 adult survivors of with safety concerns from violence, stalking, threats, or past abuse to understand their needs during the pandemic. The goal of the study was to gain a preliminary understanding of the health, safety, and economic impacts of the COVID-19 pandemic for survivors of IPV, sexual assault, and other forms of interpersonal violence.

\section{Literature Review}

The Centers for Disease Control and Prevention estimates that approximately 81 million individuals in the United States experience sexual violence, physical violence, or stalking by an intimate partner during their lifetime and that 1 in 3 women and 1 in 4 men have suffered some form of violence by an intimate partner during their lifetime (Black et al. 2011). The high prevalence of IPV and sexual assault is not only a concern for individual safety and well-being, but is also a public health issue that impacts the economic and social health of communities. Individuals who experience IPV and sexual assault are more likely to report a range of acute and chronic mental and physical health concerns that have long-term consequences for survivors and pose significant social and public health costs (Black et al. 2011; Breiding et al. 2014; D'Inverno et al. 2019). The consequences of experiencing IPV and sexual assault are varied and include death, increased physical and mental health risk, reduced economic security and educational attainment, increased housing instability, and risk of future violence victimization (Goodman et al. 2009; Iverson et al. 2013; Jewkes 2002; Simmons et al. 2018). Over $40 \%$ of female victims and $14 \%$ of male victims experience severe physical injury related to IPV (Smith et al. 2018).

COVID-19 likely creates new safety concerns and increases existing problems for survivors. For survivors of violence, getting and staying safer is often the result of a complex decision-making process that involves help-seeking in both informal and formal networks (Hanson et al. 2019; Johnson and Belenko 2019). Survivors have multiple priorities to consider when accessing services and likely employ myriad strategies to gain safety and security in both the short- and longterm (Hanson et al. 2019). As such, mandatory stay-at-home orders, quarantine protocols, and social distancing recommendations may increase the frequency and severity of IPV and risk for sexual assault (Boserup et al. 2020; Kaukinen 2020; Mazza et al. 2020). Further, perpetrators of abuse may use this increased isolation and social distancing restriction to exercise power and control over their partner, further reducing the survivor's ability to access formal and informal services (World Health Organization (WHO) 2020).

While additional research is accumulating on survivor experiences during the pandemic, there is emerging evidence that social distancing protocols have increased the risk for violence. Hotlines across the nation have seen a surge of use from people in unsafe situations who are unable to leave their homes (Jaramillo 2020) though some research indicates that survivors often feel less safe reaching out for help or calling the police while in close proximity to the abusive partner (National Domestic Violence Hotline (NDVH) n.d.; SAMHSA 2020). For example, the National Domestic Violence Hotline reported a 9\% increase in total phone, chat, and text contacts between March and May 2020 (NDVH n.d.). Of those contacts, NDVH reports that calls/chat/texts involving emotional/verbal abuse have increased by $90 \%$, those involving physical abuse increased by $61 \%$, and those involving economic/financial abuse increased by $24 \%$ in relation to preCOVID-19 levels (NDVH, n.d.).

Police departments are reporting increased family violence related calls (Boserup et al. 2020; Piquero et al. 2020). These alarming upticks may not yet represent the full scale of increased violence. Under pre-pandemic circumstances, individuals from underserved populations already encountered restrictive barriers to accessing services and support (O'Neal and Beckman 2017; Calton et al. 2016; Liang et al. 2005), with COVID-19 creating more barriers relative to their financially secure counterparts (Haynes et al. 2020). Making matters worse, these vulnerable populations, (e.g., Black, Indigenous, People of Color (BIPOC) and those with a history violence victimization) are at a heightened risk of contracting the virus (NCIRD 2020).

The United States and countries around the globe are experiencing an unprecedented crisis due to the COVID-19 pandemic. Within the context of social distancing, survivors of IPV, sexual assault and other forms of violence face new safety challenges, including increased internal and societal pressure to remain, at least temporarily, in abusive relationships in order to reduce disease spread, maintain children's' access to both parents, and keep unsafe employment positions. To date, we have little information directly from survivors about their experiences managing health, safety, and resource needs during the pandemic. To address this gap in knowledge, we surveyed people with concerns due to violence, stalking, threats, or past abuse through IPV and sexual assault services and social media to understand the impact of the COVID-19 pandemic on health, economics, safety, and service access. Findings will provide initial guidance to policymakers and violence prevention and intervention professionals' working with survivors.

\section{Methods}

The survey was promoted through partnerships with nonprofit agencies including email, print flier, web announcement distribution, social media and word-of-mouth by the study 
team, with a focus on agencies serving survivors of interpersonal violence (such as IPV shelters, parenting programs and rape crisis centers), and state IPV, sexual assault, or child welfare coalitions, first in a large Southwestern state, and then across the nation. The survey was advertised for two populations 1). any adult survivor (victim) of domestic violence, child abuse, sexual assault, human trafficking, or any other type of interpersonal violence, and 2). staff who work in a professional role with survivors of domestic violence, child abuse, sexual assault, and/or human trafficking or any other type of interpersonal violence. Non-profit agencies were the primary recruitment site, in part to minimize safety concerns that may arise from completing a safety survey while sheltering in place with an abusive partner. Four non-profits confirmed they shared the survey with at least some of their adult client population and 10 indicated a willingness to share. The agencies that shared with clients did so via email and their agency social media. The research team sent the recruitment materials to agencies and coalitions with which they had existing partnerships, and asked them to forward and distribute widely in their networks. The survey was administered via Qualtrics. Qualtrics allows for exit and entrance into the survey with progress saved, a key feature in event of disruptions or safety concerns.

The consent form emphasized that all questions were voluntary and any questions could be skipped. The survey tool was developed by the study team and had two separate pathways; one for people with current safety concerns because of violence, stalking, threats, or past abuse and a second for staff working at agencies that help survivors' (victims) of violence, including intimate partner violence, sexual assault, child maltreatment, family violence and human trafficking (results related to staff are presented elsewhere). After consent, survey participants first saw a sequence of demographics questions then the question Are you currently experiencing safety concerns or other problems related to violence, stalking, threats, or past abuse? (This could include domestic violence, sexual assault, human trafficking or abuse to you or your child)? The following results are for all participants answering "yes" to that question. Participants had the option to sign up for a giftcard raffle in a separate survey (A total of $30 \$ 20$ giftcards were distributed). The survey was fielded from April 8th through June 8th, 2020 and took on average $8 \mathrm{~min}$ to complete. All survey questions were voluntary. The research study was approved by the first author's IRB.

\section{Survey}

Questions on the survey were anchored by two time periods: before the COVID-19 pandemic, and after the pandemic began, with the data of March 13th (the date a state of emergency in the study teams' state was established) to mark the beginning of the pandemic. The current safety concern survey was divided into four sections and sought to balance collecting needed data with minimizing participant burden. Section one was demographics (age, race/ethnicity, gender, living situation). In section two, participants responded to likert-type scales assessing work and health (e.g., have you been tested for Coronavirus? Did you lose your job or have your hours/ reduce? Did anyone in your immediate family lose their job or have hours reduced?). Participants were also asked open ended-questions about problems or needs related to money, food, and supplies since the pandemic began. In section three, participants were asked about safety and safety planning strategies (e.g., How has your safety from violence, threats, stalking or abuse changed since the Coronavirus pandemic began? Since the coronavirus pandemic began, how difficult are your relationships with the people you live with?). Participants were asked which safety strategies they had used since the COVID-19 pandemic began from a list of 8 , including an 'other' write-in option. We also included a question about what resources or services would help with safety concerns and included 10 options (e.g., different housing, emergency shelter). In section four, respondents were asked about the use of virtual and phone services during COVID-19, with question assessing virtual service use and an open-ended question to understand experiences with virtual services and other impacts as a result of the pandemic. The survey was administered in both English and Spanish, with translation conducted by a certified translator and back translated, aligned with best practices.

\section{Data Analysis}

Data are summarized using descriptive methods in SPSS. Valid percentages are provided, showing the response percent out of those responding to the question. Analysis approaches common to thematic analysis (Braun and Clarke 2006) and content analysis (Prior 2014) were used for answer responses from open-ended questions. The first author generated initial codes after data familiarization and review, including key concepts and words, and then searched for key concepts themes related to economics, health, and safety during the COVID-19 pandemic. Then, the authorship/research team reviewed themes and concepts, defining and naming them (Braun and Clarke 2006), to produce results.

\section{Results}

\section{Participant Demographics}

A total of 53 people responding to the survey indicated they had active safety concerns from violence, threats, stalking, or abuse, and 38 of those participants responded to open-ended comments on their survey responses. See Table 1 below for 
the gender, race/ethnicity, and housing status/type information. Participants were majority female-identified, slight majority White $(52.9 \%)$, and living in a house or apartment (57.4\%).

Major findings from survey data included safety concerns related to violence, stalking, threats or past abuse; service and support needs related to both violence and the pandemic; and broader economic and health concerns.

\section{Participant Safety}

Reported relationship difficulty in the home unit increased for $80.9 \%$ of participants during the pandemic. The majority of participants $(92.8 \%)$ reported feeling at least "a little bit" safe at home. Only 9 , or $20 \%$ of participants, reported being safer from violence, threats, stalking, or abuse than before the pandemic began, with the majority reporting the same or decreased safety levels. The three most common strategies used by participants to help with safety concerns included using social media to connect with others (60\%); trying to avoid people I live with (51.2\%), and staying in another room from people I live with (43.9\%). The three most frequently endorsed items for what would improve safety were emotional support (75\%); financial help (64\%); and different housing (55\%). An average of three safety strategies were endorsed as helpful to

Table 1 Participant demographic information and housing status

\begin{tabular}{lc}
\hline & $\mathrm{n}=$ \\
\hline Gender & \\
Male & $8(15.7 \%)$ \\
Female & $42(82.4 \%)$ \\
Did not identify gender & $3(5.6 \%)$ \\
Race Ethnicity & \\
Black/African American & $10(19.6 \%)$ \\
Hispanic or Latinx & $10(19.6 \%)$ \\
Asian or Asian American & $2(3.9 \%)$ \\
White/Caucasian & $27(52.9 \%)$ \\
Multiracial & $2(3.9 \%)$ \\
Did not identify a race/ethnicity & $2(3.9 \%)$ \\
Housing Situation & \\
House or Apartment & $27(57.4 \%)$ \\
Staying with romantic partner & $3(6.4 \%)$ \\
Staying with friends/family & $6(12.7 \%)$ \\
Shelter/Housing Program/Other & $11(23.4 \%)$ \\
Who do you live with? & \\
Romantic partner (with or without children) & $23(48.9 \%)$ \\
Children & $12(25.5 \%)$ \\
Alone & $7(14.9 \%)$ \\
Other & $5(10.7 \%)$ \\
\hline &
\end{tabular}

Valid percentages are presented among those providing a response participants (range 0-7) (see Table 2 for strategies most often used). Over $68 \%$ of participants found three or less strategies helpful, with over $31 \%$ finding four or more helpful. Safety concerns were referenced in opened ended comments by a few participants as a primary concern. One participant stated:

The living together with my son while sharing custody with separated parents. The physical and mental health safety of my son due to his father's abuse. Expenses and bills like rent and utilities, car payments and ATT phone bill. The termination of my lease to find other housing and not being able to comply with the requirements due to reduction of work.

Table 2 Safety strategies

$\mathrm{n}=$

How safe are you from violence, threats, stalking or abuse in your current household?

Very Safe

$14(33.3 \%)$

Somewhat Safe

$16(38.1 \%)$

A Little Bit Safe

$21.4(9)$

Not at All Safe

$3(7.1)$

How has your safety from violence, threats, stalking or abuse changed since the pandemic began?

I am safer $\quad 9(20 \%)$

My safety is the same $18(40 \%)$

My safety has decreased a little $15(33 \%)$

My safety has decreased a lot $3(6.7 \%)$

Strategies used to improve safety

Using social media to connect $24(60 \%)$

Trying to avoid conflict with people I live with $21(51.2 \%)$

Staying in another room from people I live with $18(43.9 \%)$

Using a hotline/chat/text service $14(33.3 \%)$

Staying in another residence $\quad 11(26.8 \%)$

Staying off social media $\quad 10(25 \%)$

Calling the police $\quad 7(17.9 \%)$

Emergency shelter $\quad 7(17.1 \%)$

What would help improve your safety from violence, threats, stalking or abuse?

Emotional Support $\quad 30(75 \%)$

Financial Help $25(64.1 \%)$

Different Housing $22(55 \%)$

Help with Legal Issues $\quad 20(52.6 \%$

Activities for Children $20(52.6 \%)$

Childcare $19(48.7 \%)$

Law Enforcement Support $\quad 16(42.1 \%)$

Help with unemployment $15(39.5 \%)$

Parenting support $13(35.1 \%)$

Shelter $10(27 \%)$ 
Another participant said:

Right now, my biggest concern is that my children may be being abused by their father. With limited time and money due to the coronavirus, getting organized and financially prepared for legal action is very difficult (something that is still difficult outside this situation as a single mom of young children). I'm concerned that the court system is going to be tied up before extended summer visitations and that my ex is taking our children to public gatherings and other people's homes whereas I am keeping them very isolated. I'm concerned about their exposure and mine due to his dismissal of the severity of the spread of the virus.

Table 2 (below) provides an overview of participant's responses related to their safety from violence in their current household, the change they have seen in their safety since the onset of COVID-19, the strategies they have used to improve their safety, and their perceptions of what would help improve their safety in the context of COVID-19.

\section{Service and Support Needs}

Service needs spanned essential aid, government agencies and IPV and sexual assault focused support. When asked about needs during the pandemic, a few participants reported concerns with service access. Participants reported the closure of government and social service offices contributing to delays in getting services and supplies. A few participants reported not knowing where to go for help, as one shared 'Don't know where to go for help. Advocates do provide information when police reports are made of the abuse." In some cases, stress came from not having the correct supplies for transitioning to remote work such as a computers or software. For others, employer demands created increased stress:

I was quarantined. So my job doesn't let me take it easy at work. They are more demanding than ever. Like I have planned being sick. They refused to let me work my part time job to make up money. Then I paid in advance for something for the company and they refused to pay me back. Now saying ugly things every day. Hard to eat and function. Dr says I am under stress.

While the majority of participants indicated financial or emotional support would help improve safety, just over $42 \%$ had used virtual counseling or advocacy services at a violence prevention or intervention agency since the pandemic began. Experiences with virtual services were mixed, with participants reporting positive aspects, stating that teleservices were "excellent," "supportive," "very good." and "It's going fine." One participant noted:

"I really prefer it this way honestly! I do not drive and have no transportation right now to go to their office! I am happy that I can still have my tele-therapy services at the comfort and safety of my place! I really hope that medical insurance will cover services after corona virus dies down!"

Some participants preferred in-person services, stating that telehealth services were "crappy," services were "better in person," or "I didn't like it because I couldn't talk face to face." Another stated "It's different. Don't like it as much as being in person." Other concerns included confidentiality, tech safety (zoom "bombing"), and delays and interruptions with technology.

\section{Economic and Health Concerns}

Along with safety, violence, and service use issues related to life during the pandemic, participants also respondent to questions identifying other COVID-19 linked impacts on their overall livelihood, including impacts to health and economic well-being.

Health and Health Care Access As shown in Table 3, most participants (74\%) had not been tested for COVID-19, of the $24 \%$ that had been tested, 3 tested positive. However, $24 \%$ of participants had been advised by a healthcare provider to get a test and been unable to get one. Open-ended responses from the survey indicated stress over the pandemic contributed to mental health issues for some participants, with one person noting that, "The pandemic has only impacted my mental health pretty severely but everything else is the same."

Economic Challenges While the majority of participants reported working $(66 \%), 18 \%$ indicated they had lost a job since the pandemic began. Nearly half ( $42 \%$ ) of participants reported a person they live with lost their jobs or had their hours reduced. Of those working, $62 \%$ had positions considered essential in regard to stay at home orders. Participants were asked open-ended questions about what problems they had since the pandemic began related to money, food, and other supplies. Sixteen participants reported problems obtaining food and other supplies, due to lack of resources to obtain them, or a lack of availability at stores. One participant shared they were having "difficulty financially buying one to 2 week supplies at one time. Challenging getting toilet paper, paper towels and some foods." Job loss or wage reduction was another commonly reported issue, with 9 participants reporting on the economic impact during the pandemic, as one participant shared, "I was unable to work and therefore had minimal 
Table 3 Participant health and COVID-19

\begin{tabular}{lcll}
\hline & Yes & No & Waiting on Results \\
\hline Been tested for COVID-19 & $12(24 \%)$ & $37(74 \%)$ & $1(2 \%)$ \\
Tested positive for COVID-19 & $3(6 \%)$ & $45(90 \%)$ & $2(4 \%)$ \\
Immediate family member tested & $6(12 \%)$ & $43(86 \%)$ & $1(2 \%)$ \\
Unable to get test & $12(24 \%)$ & $38(76 \%)$ & N/A \\
\hline
\end{tabular}

income." Family member job loss also impacted participants, as one participant noted: "Mother's salary was reduced by half which has made it hard to pay our bills." Being able to safely go to work was an issue for some participants, such as one person who noted that "My job which is essential has chosen not to take all necessary precautions against coronavirus. Which affects my health and others tremendously." The lack of childcare and school appeared to contribute to increased stress and economic challenges. A participant shared "I have had to miss a lot of work because of my childcare. It has put a strain on money for bills." While less frequently mentioned, lack of transportation, medical care access, and housing were concerns for some participants. In some cases, the economic impact resulted in the loss of housing or made it more difficult to respond to a current homelessness spell. Participants shared their experience of homelessness:

Access to resources all but disappeared, became homeless and quarantine happened two weeks later. This shelter did not provide access to community resources, I got a list of housing etc from an advocate at another shelter. Even so, what places were open did not have any availability

Another stated, "The timing could not have been worse to become homeless. I'm getting kicked out now and have nowhere to go. Thanks to the bureaucracy here, they made no exceptions, even through the pandemic."

\section{Discussion}

This brief survey brings initial insight into the experiences of survivors of violence during the COVID-19 pandemic and provides guidance for next steps for research and practice. In this sample of 53 people with active safety concerns from violence, threats, stalking, or abuse, there were significant safety and support needs directly from experiences of violence or abuse during the pandemic, and broader health and economic impacts occurring in tandem with violence-generated impacts. Not surprisingly, perception of safety either stayed the same or decreased for many during the pandemic. A recent study of IPV rates in Dallas, Texas found an increase of calls to police during the first during stay-at home orders, with rates receding to expected averages after two weeks (Piquero et al. 2020). Common safety strategies included social media for support and avoidance of the abuser in the home, which emphasizes the importance of social support and de-escalation techniques, rather than formal support like law enforcement.

While participants may have been referred to law enforcement when other services, like shelter, for survivors of violence were not available, it was one of the least frequently endorsed supports needed by participants in this study. This is not surprising given that for many survivors, especially those identifying as BIPOC, are disproportionally impacted by both interpersonal violence and police brutality (Kendal 2020; Decker et al. 2019), and the increasing focus on racial injustice and police conduct during the pandemic(Baker 2020) when the survey was fielded. Service providers working with survivors of violence should consider other potential referrals along with the police, in recognition that help-seeking from law enforcement bring different safety concerns for survivors. Advocacy interventions, during and after the pandemic, should be mindful of the structural consequences of IPV and sexual assault, the intersection with discrimination and, given the intensive economic impacts, resources such as housing, rent and food support, and emergency shelter may be more impactful for some survivors than the risks of police intervention, even as emergency remedies. Effectively addressing IPV, sexual assault, and other types of violence requires prevention and intervention methods that not only target specific risk factors in individuals but account for risk factors present at the community and societal levels as well (Dutton et al. 2015). Successful efforts to reduce the prevalence of IPV and sexual assault are those that build individual resilience, increase community response capacity, and broaden access to structural and social factors like health care systems, affordable housing, safe work environments, and supportive services (Dutton et al. 2015).

Major themes related to the impact of the COVID-19 pandemic for those with safety concerns included challenges with health and work, stress from economic instability and job loss, difficulties staying safe during the period of stay-at-home orders and physical distancing, and resource and support needs. Considering that unemployment rates were between 13 and $14 \%$ when the survey was fielded, rates higher than the recession of 2008 (Kochhar 2020), this finding was not surprising. Survivors of IPV, sexual assault and other forms of 
interpersonal violence already disproportionately experience economic and housing insecurity (Danis and Bhandari 2010; Klein et al. 2019), which is exacerbated by the economic conditions of the COVID-19 pandemic. Our findings indicate that employment, childcare, workplace conditions, and access to resources and housing are major concerns for violence survivors who are also addressing complex safety needs. However, these increased needs are happening in a climate of reduced access to services and supports, increasing risk factors for this already vulnerable population. The lack of ability to go to work has the risk for further isolation for those already more likely to be alienated from friends and family. (Ulmestig and Eriksson 2017) found that one of the impacts of unemployment for survivors of violence was the loss of social support and recognition from colleagues. This may be a consequence for survivors during the COVID-19 pandemic, regardless of whether they had actually lost their job (e.g., working from home or had colleagues laid off). Economic impacts of the pandemic heightened safety and mental health concerns.

\section{Recommendations}

Isolation and lack of support, coupled with economic impact, creates potential for mental health consequences related to COVID-19 and stay-at home orders, which are exacerbated by safety concerns from threats of violence and harm. Increasing access and availability of services, particularly a broad network of phone, chat, text, and video support and financial and housing support, is therefore paramount to meeting survivor needs during times of quarantine. Participants in this study gave virtual services mixed reviews- a result echoed in other research-(Al-Alosi 2020; Frazier and Yount 2017; Rempel et al. 2019), indicating the importance of survivor choice, access and experience with these virtual platforms. Further staff training is needed on diverse platforms to meet survivor self-defined needs.

Increasing the availability and accessibility of these services is a critical component to addressing needs, given the potential benefit that can come from quality service provision. Sexual assault and IPV services, including counseling, shelter, advocacy, medical, and legal/judicial coordination increases survivors' safety, reduces risk of homicide, and improves long-term physical and mental health outcomes (Constantino et al. 2005; Goodman et al. 2016; Sullivan and Bybee 1999). Increasing resources to IPV and sexual assault agencies and economic remedies, rather than intensifying criminal justice responses, may be more impactful for safety, and more aligned with survivor needs. Along with these services, participants underscored the need for supportive services for children in the context of the coronavirus pandemic. Around half of participants identified that childcare or children's activities would not only benefit their children and help facilitate their own safety from violence. Given the persistently high co- occurrence between adult interpersonal violence and forms of child abuse and neglect (Finkelhor et al. 2015), the findings of the current study also highlight the risk to children posed by social distancing and isolation in the face of COVID-19.

A critical component to providing support and services to survivors is developing a safety plan, a personalized plan to address immediate, specific risks faced by survivors of violence, with the aim of reducing the extent and impact of violence and abuse going forward (Campbell 2002; Davies 2019; Davies and Lyon 2014; Messing et al. 2015). Safety plans have been demonstrated to enhance survivors' sense of safety and well-being, as well as increase the number of safety-related behaviors survivors preform over time, leading to reduced harm from violence and enhanced wellbeing (Davies and Lyon 2014; Glass et al. 2010). Historically, safety plans have been geared to help people leave violent situations and have focused heavily on escape strategies and formal supports like law enforcement. While safety planning skills are largely focused on physical distance-driven approaches, a paradigm shift in the last decade has introduced new mechanism of safety planning for those that do not want or plan to leave a potentially abusive situation (Davies 2019). These approaches, which involve risk analysis, de-escalation approaches, identification of options, and partnership with support mechanisms, uses survivor priorities and knowledge of partner to increase safety (Davies 2019). The "advocacy beyond leaving" (Davies 2019) safety planning approach and the findings of this study should be integrated into advocacy and service provision to enhance safety planning skills in the context of stay-at home orders and quarantine. Notably, participants in this survey endorsed emotional and financial supports as being the most helpful to safety improve, highlighting the need for advocates to address the needs while making individualized safety plans.

\section{Limitations}

This study has several limitations of note. The first is the small sample size of 53, which limits our ability to extrapolate these findings to a larger group and conduct more detailed analysis to understand more about risk and protective factors that are associated with health, safety and economic concerns related to the pandemic. The relatively small sample is likely due in majority to two factors. The first is the advertising of the survey for both staff and those with safety concerns, which may have created confusion about eligibility for some clients. The second factor is the small number of agencies that confirmed sending the survey did so electronically and through social media. The brevity of the survey tool, while helpful for administration, and critical to reducing participant burden in the middle of a global pandemic, limited our ability to ask behaviorally-specific questions about types of violence experienced during COVID-19 and other factors that might have contributed to health, economic and resources needs and concerns. The study relies on individuals to 
identify themselves as survivors of violence, rather than asking a set of behaviorally specific questions to verify their experiences. While this is in line with service provider models, it does limit our ability to investigate experiences unique to specific forms or severities of victimization experiences. We also lack comparison on safety and economic impacts of COVID-19 to people without safety concerns, which limits our understanding of the unique contribution of interpersonal violence to pandemic-related stress. Future research projects should use behaviorally specific and mixed methods longitudinal approaches to gather more indepth data about survivor needs and the pandemic impact. Additionally, subsequent research should include more targeted engagement with IPV and sexual assault focused agencies to share survey opportunities in multiple ways beyond social media pages, including email, print fliers, texting, and client portals. Promotion materials should be tailored to each specific population to minimize the potential for confusion about eligibility.

\section{Conclusion}

The COVID-19 pandemic has brought unprecedented health, safety and resource challenges for survivors of violence. In this study of 53 survivors with safety concerns, isolation, lack of resources, and the close quarters of stay-at home orders, coupled with diminished social networks and economic concerns have intensified the consequences and impact of violence. Finding from this research highlight the economic and safety challenges of the COVID-19 pandemic, and emphasize the need to enhance community service access, including telehealth approaches to expand the options for survivors during lockdowns or quarantines. The formal and informal community response to interpersonal violence during and after the COVID-19 pandemic, like IPV and sexual assault, needs to be accelerated and improved to accommodate a variety of survivor safety and resources needs among a shifting landscape. Resource and service enhancements will have benefit long after the COVID-19 pandemic has ended, improving community health and safety.

\section{References}

Al-Alosi, H. (2020). Fighting fire with fire: Exploring the potential of technology to help victims combat intimate partner violence. Aggression and Violent Behavior, 52, 101376. https://doi.org/10. 1016/j.avb.2020.101376.

Baker, C. (2020). In a pandemic, all some people see is your color. The Atlantic. Retrieved from https://www.theatlantic.com/magazine/ archive/2020/06/coronavirus-racism/610609/.

Black, M.C., Basile, K.C., Breiding, M.J., Smith, S.G., Walters, M.L., Merrick, M.T., ...\& Stevens, M.R. (2011). The national intimate partner and sexual violence survey (NISVS): 2010 summary report. Atlanta: National Center for Injury Prevention and Control, Centers for Disease Control and Prevention.
Boserup, B., McKenney, M., \& Elkbuli, A. (2020). Alarming trends in US domestic violence during the COVID-19 pandemic. American Journal of Emergency Medicine. W.B. Saunders. https://doi.org/10. 1016/j.ajem.2020.04.077.

Braun, V., \& Clarke, V. (2006). Using thematic analysis in psychology. Qualitative Research in Psychology, 3, 77-101.

Breiding, M. J., Chen, J., \& Black, M. C. (2014). Intimate partner violence in the United States -2010. Atlanta: National Center for Injury Prevention and Control, Centers for Disease Control and Prevention.

Calton, J. M., Cattaneo, L. B., \& Gebhard, K. T. (2016, December 1). Barriers to help seeking for lesbian, gay, bisexual, transgender, and queer survivors of intimate partner violence. In Trauma, violence, and Abuse (Vol. 17, pp. 585-600). Ltd.: SAGE Publications. https:// doi.org/10.1177/1524838015585318.

Campbell, J. (2002). Health consequences of intimate partner violence. The Lancet (British Edition), 359(9314), 1331-1336. https://doi.org/ 10.1016/s0140-6736(02)08336-8.

Cheng, T. C., \& Lo, C. C. (2016). Racial disparities in intimate partner violence examined through the multiple disadvantage model. Journal of Interpersonal Violence, 31(11), 2026-2051. https://doi. org/10.1177/0886260515572475.

Constantino, R., Kim, Y., \& Crane, P. A. (2005). Effects of a social support intervention on health outcomes in residents of a domestic violence shelter: A pilot study. Issues in Mental Health Nursing, 26, 575-590.

D'Inverno, A. S., Smith, S. G., Zhang, X., \& Chen, J. (2019). The impact of intimate partner violence: A 2015 NISVS research-in-brief. Atlanta: National Center for Injury Prevention and Control, Centers for Disease Control and Prevention.

Danis, F. S., \& Bhandari, S. (2010). Understanding domestic violence: A primer. In L. L. Lockhart \& F. S. Danis's (Eds.), Domestic violence: Intersectionality and culturally competent practice (pp. 29-66). New York: Columbia University Press.

Davies, J. (2019). Victim-defined advocacy beyond leaving: Safer through strategies to reduce violent behavior. Harrisburg: Building Comprehensive Solutions to Domestic Violence, National Resource Center on Domestic Violence.

Davies, J. M., \& Lyon, E. (2014). Domestic violence advocacy: Complex lives/difficult choices (2nd ed.). Thousand Oaks: Sage.

Decker, M. R., Holliday, C. N., Hameeduddin, Z., Shah, R., Miller, J., Dantzler, J., \& Goodmark, L. (2019). "You do not think of me as a human being": Race and gender inequities intersect to discourage police reporting of violence against women. Journal of Urban Health, 96(5), 772-783. https://doi.org/10.1007/s11524-019-00359-z.

Dutton, M. A., James, L., Langhorne, A., \& Kelley, M. (2015). Coordinated public health initiatives to address violence against women and adolescents. Journal of Women's Health, 24(1), 8085. https://doi.org/10.1089/jwh.2014.4884.

Finkelhor, D., Turner, H., Shattuck, A., \& Hamby, S. (2015). Prevalence of childhood exposure to violence, crime, and abuse. JAMA Pediatrics, 169(8), 746-754.

Frazier, T., \& Yount, K. (2017). Intimate partner violence screening and the comparative effects of screening mode on disclosure of sensitive health behaviours and exposures in clinical settings. Public Health, 143, 52-59. https://doi.org/10.1016/j.puhe.2016.10.021.

Geiger, H. J. (1997). Inequity as violence: Race, health and human rights in the United States. Health and Human Rights, 2(3), 7-13. https:// doi.org/10.2307/4065148.

Glass, N., Eden, K., Bloom, T., \& Perrin, N. (2010). Computerized aid improves safety decision process for survivors of intimate partner violence. Journal of Interpersonal Violence, 25(11), 1947-1964.

Goodman, L. A., Smyth, K. F., Borges, A. M., \& Singer, R. (2009). When crises collide: How intimate partner violence and poverty inter-sect to shape women's mental health and coping. Trauma, Violence and Abuse, 10, 306-329.

Goodman, L. A., Fauci, J. E., Sullivan, C. M., DiGiovanni, C. D., \& Wilson, J. M. (2016). Domestic violence survivors' empowerment 
and mental health: Exploring the role of the alliance with advocates. American Journal of Orthopsychiatry, 86(3), 286-296. https://doi. org/10.1037/ort0000137.

Hanson, G. C., Messing, J. T., Anderson, J. C., Thaller, J., Perrin, N. A., \& Glass, N. E. (2019). Patterns and usefulness of safety behaviors among community-based women survivors of intimate partner violence. Journal of Interpersonal Violence., 088626051985340. https://doi.org/10.1177/0886260519853401.

Haynes, N., Cooper, L. A., \& Albert, M. A. (2020). At the heart of the matter: Unmasking and addressing the toll of COVID-19 on diverse populations. Circulation Lippincott Williams and Wilkins, 142, 105107. https://doi.org/10.1161/CIRCULATIONAHA.120.048126.

Iverson, K. M., Litwack, S. D., Pineles, S. L., Suvak, M. K., Vaughn, R. A., \& Resick, P. A. (2013). Predictors of intimate partner violence revictimization: The relative impact of distinct PTSD symptoms, dissociation, and coping strategies. Journal of Traumatic Stress, 26, 102-110. https://doi.org/10.1002/jts.21781.

Jaramillo, C. (2020). Family violence rose $12.5 \%$ during shelter-at-home orders, UT-Dallas study finds. The Dallas morning news. https:// www.dallasnews.com/news/crime/2020/05/19/ut-dallas-study-findsfamily-violence-increased-125-during-shelter-at-home-orders/

Jewkes, R. (2002). Intimate partner violence: Causes and prevention. The Lancet, 359, 1423-1429. https://doi.org/10.1016/s0140-6736(02) 08357-5.

Johnson, I. D., \& Belenko, S. (2019). Female intimate partner violence survivors' experiences with disclosure to informal network members. Journal of Interpersonal Violence., 088626051984328. https://doi.org/10.1177/0886260519843282.

Kaukinen, C. (2020). When stay-at-home orders leave victims unsafe at home: Exploring the risk and consequences of intimate partner violence during the COVID-19 pandemic. American Journal of Criminal Justice., 45, 668-679. https://doi.org/10.1007/s12103-020-09533-5.

Kendal, M. (2020). Hood feminism: Notes from the women that a movement forgot. New York; Viking.

Klein, L. B., Chesworth, B. R., Howland-Myers, J. R., Rizo, C. F., \& Macy, R. J. (2019). Housing interventions for intimate partner violence survivors: A systematic review. In Trauma, violence, and Abuse (p. 152483801983628). Ltd.: SAGE Publications. https:// doi.org/10.1177/1524838019836284.

Kochhar, R. (2020, June 11). Unemployment rose higher in three months of COVID-19 than it did in two years of the great recession. Pew Research Center. https://www.pewresearch.org/fact-tank/2020/06/ 11/unemployment-rose-higher-in-three-months-of-covid-19-thanit-did-in-two-years-of-the-great-recession/

Liang, B., Goodman, L., Tummala-Narra, P., \& Weintraub, S. (2005, September). A theoretical framework for understanding helpseeking processes among survivors of intimate partner violence. American Journal of Community Psychology., 36, 71-84. https:// doi.org/10.1007/s10464-005-6233-6.

Mazza, M., Marano, G., Lai, C., Janiri, L., \& Sani, G. (2020). Danger in danger: Interpersonal violence during COVID-19 quarantine. Psychiatry Research, 113, 046.

Messing, J. T., Ward-Lasher, A., Thaller, J., \& Bagwell-Gray, M. E. (2015). The state of intimate partner violence intervention: Progress and continuing challenges. Social Work (United States), 60(4), 305-313. https://doi.org/10.1093/sw/swv027.

National Center for Immunization and Respiratory Diseases (NCIRD), Division of Viral Diseases. (2020). Health equity considerations and racial and ethnic minority groups. Retrieved from https://www.cdc. gov/coronavirus/2019-ncov/community/health-equity/raceethnicity.html

National Domestic Violence Hotline. (n.d.) COVID-19 special report. Retrieved from https://www.thehotline.org/wp-content/uploads/ sites/3/2020/06/2005-TheHotline-COVID19-report_final.pdf
National Medical Association. (2020). COVID-19 underscores wealth and health disparities in the African American community. Retrieved from https://www.nmanet.org/news/500673/COVID19Underscores-Wealth-and-Health-Disparities-in-theAfricanAmerican-Community.htm

O’Neal, E. N., \& Beckman, L. O. (2017). Intersections of race, ethnicity, and gender: Reframing knowledge surrounding barriers to social services among Latina intimate partner violence victims. Violence Against Women, 23(5), 643-665. https://doi.org/10.1177/ 1077801216646223.

Piquero, A. R., Riddell, J. R., Bishopp, S. A., Narvey, C., Reid, J. A., \& Piquero, N. L. (2020). Staying home, staying safe? A short-term analysis of COVID-19 on Dallas domestic violence. American Journal of Criminal Justice., 45, 601-635. https://doi.org/10.1007/ s12103-020-09531-7.

Prior, L. (2014) Content analysis. P. Leavy (Ed.), The Oxford handbook of qualitative research (pp. 359-379). Oxford University Press.

Rempel, E., Donelle, L., Hall, J., \& Rodger, S. (2019). Intimate partner violence: A review of online interventions. Informatics for health and social care. Taylor and Francis Ltd., 44, 204-219. https://doi. org/10.1080/17538157.2018.1433675.

Simmons, S., Knight, K., \& Menard, S. (2018). Long-term consequences of intimate partner abuse on physical health, emotional well-being, and problem behaviors. Journal of Interpersonal Violence, 33(4), 539-570. https://doi.org/10.1177/0886260515609582.

Smith, S. G., Chen, J., Basile, K. C., Gilbert, L. K., Merrick, M. T., Patel, N., Walling, M., \& Jain, A. (2017). The National Intimate Partner and sexual violence survey (NISVS): 2010-2012 state report. Atlanta: National Center for Injury Prevention and Control, Centers for Disease Control and Prevention.

Smith, S. G., Zhang, X., Basile, K. C., Merrick, M. T., Wang, J., Kresnow, M., \& Chen, J. (2018). The National Intimate Partner and sexual violence survey (NISVS): 2015 data brief - Updated release. Atlanta: National Center for Injury Prevention and Control, Centers for Disease Control and Prevention Available at: https://www.cdc.gov/ violenceprevention/pdf/2015data-brief508.pdf.

Stockman, J. K., Hayashi, H., \& Campbell, J. C. (2015). Intimate partner violence and its health impact on disproportionately affected populations, including minorities and impoverished groups. Journal of Women's Health, 24(1), 62-79. https://doi.org/10.1089/jwh.2014.4879.

Substance Abuse and Mental Health Services Administration (SAMHSA). (2020). Intimate partner violence and child abuse considerations during COVID-19. Retrieved from https://www.samhsa. gov/sites/default/files/social-distancing-domestic-violence.pdf

Sullivan, C., \& Bybee, D. (1999). Reducing violence using communitybased advocacy for women with abusive partners. Journal of Consulting and Clinical Psychology, 67, 43-53.

Tai, D. B. G., Shah, A., Doubeni, C. A., Sia, I. G., \& Wieland, M. L. (2020). The disproportionate impact of COVID-19 on racial and ethnic minorities in the United States. Clinical Infectious Diseases. https://doi.org/10.1093/cid/ciaa815.

Ulmestig, R., \& Eriksson, M. (2017). Financial consequences of leaving violent men: Women survivors of domestic violence and the social assistance system in Sweden. European Journal of Social Work, 20(4), 560-571. https://doi.org/10.1080/13691457.2016.1188778.

World Health Organization (WHO). (2020). COVID-19 and violence against women: What the health sector/system can do. Retrieved from https://www.who.int/reproductivehealth/publications/vawcovid-19/en/

Publisher's Note Springer Nature remains neutral with regard to jurisdictional claims in published maps and institutional affiliations. 